\title{
Determination of Piroctone Olamine (Octopirox) in Bulk by UV Spectrophotometric Method
}

\author{
Lyudmyla M. Antypenko ${ }^{1}$ and Vitaliy A. Solodovnyk ${ }^{2}$ \\ ${ }^{1}$ Organic and Bioorganic Chemistry Department, Zaporizhzhya State Medical University, 26, Mayakovsky \\ Avenue, Zaporizhzhya, 69035, Ukraine \\ ${ }^{2}$ Technology of Drugs Department, Zaporizhzhya State Medical University, 26, Mayakovsky Avenue \\ Zaporizhzhya, 69035, Ukraine
}

(Received: December 24, 2016; Accepted: March 16, 2017; Published (web): June 21, 2017)

\begin{abstract}
A simple and low-cost UV-spectrophotometric method has been developed and validated for the quantification of Octopirox in bulk. The linearity was found at $307 \pm 1 \mathrm{~nm}$ in 10-50 $\mu \mathrm{g} / \mathrm{ml}$ solution of ethanol-water $(1: 3, \mathrm{v}: \mathrm{v})$ with $\mathrm{r}^{2}=0.99$. The limit of detection was found to be $1.18 \mu \mathrm{g} / \mathrm{ml}$, while the limit of quantification was 3.58 $\mu \mathrm{g} / \mathrm{ml}$. The method was validated for linearity, accuracy, precision, range, ruggedness and robustness.
\end{abstract}

Key words: Octopirox, validation, UV-spectrophotometry

\section{INTRODUCTION}

The piroctone olamine (CAS \# 68890-66-4) is 1hydroxy-4-methyl-6-(2,4,4-trimethyl)-pentyl-2(1H)pyridone 2-aminoethanol salt (Figure 1).

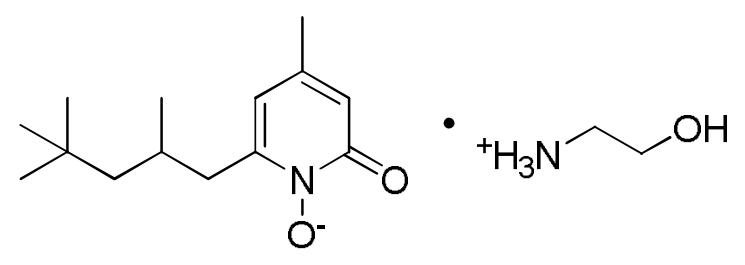

Figure 1. Structural formula of Octopirox.

Under the brand name Octopirox, it was used for the first time in July 1979 in the Seborin produced by Schwarzkopf \& Henkel Düsseldorf (subsidiary of Hoechst). ${ }^{1}$ Now-a-days, the compound is present in many cosmetic products for the treatment of dandruff (Pityriasis simplex capillitii), like shampoos, even for dogs and cats. It has fungicidal activity against all medically relevant dermatophytes, yeasts and mold fungi, due to penetration into the cell wall of yeast,

Correspondence to: Lyudmyla M. Antypenko

Tel.: +38-066-9658-740.

E-mail: antypenkol@gmail.com

Dhaka Univ. J. Pharm. Sci. 16(1): 37-42, 2017 (June) fungi such as Malassezia furfur and complexation with iron (III) ions, which results in an inhibition of the energy metabolism in the mitochondria of the fungi. ${ }^{1}$ The concentrations should be between 0.1 and $1.0 \%$, depending on the type of final product, or should be further reduced for preparations that remain on the hair or the scalp. Minimum inhibition concentration for the most important species of fungi lies between 0.5 and $4.0 \mu \mathrm{g} / \mathrm{ml}^{2}{ }^{2}$ In addition to the fungicidal activity, piroctone olamine also exhibits a bactericidal activity against gram-positive and gramnegative bacteria in $0.1-3.0 \%$ concentration in personal care compositions. ${ }^{3}$ Moreover, in vitro model of experimental onychomycosis caused by $T$. rubrum pointed out a possible role of $0.5 \%$ octopirox nail lacquer as a preventive tool for subjects at risk or as a curative tool in the first stage of onychomycosis. ${ }^{4}$ None of the in vivo studies gave any indication of its embryotoxic, teratogenic and mutagenic effect. ${ }^{5}$

Among methods of identification, there were reports of IR, UV spectra, TLC and melting point $\left(133-136^{\circ} \mathrm{C}\right)$ determinations. ${ }^{6-11}$ Considering UV data, absorption maximum of Octopirox was found at $317 \pm 2 \mathrm{~nm}$ and specific absorbance was calculated to be 214 to $236 .^{7}$ Moreover, for $0.1 \mathrm{M}$ methanolic 
sodium hydroxide solution in concentration $20 \mu \mathrm{g} / \mathrm{ml}$ it was reported at $230-360 \mathrm{~nm}^{8}$ The results showed that such solution was stable for 3 years according to Hoechst stability test and $\mathrm{E}_{\mathrm{cm}}^{\%}$ was $226-230$ at 317 nm. Furthermore, Clariant $\mathrm{GmbH}$ proposed to determine Octopirox in shampoos in concentration of 0.1 to $5 \mathrm{~g} / 100 \mathrm{~g}$ by RP HPLC in methanol-water $\{95: 5, \mathrm{v}: \mathrm{v}\}$ after reduction by $15 \%$ solution of Ti(III) chloride with product UV detection at $300 \mathrm{~nm} .{ }^{9}$ Also RP HPLC method has been developed for simultaneous identification and quantitative determination of four anti-dandruff agents such as salicylic acid, ketoconazole, climbazole and octopirox in commercial anti-dandruff shampoo products in acetonitrile : water $\{60: 40, \mathrm{v}: \mathrm{v}$ with potassium dihydrogen phosphate and orthophosphoric acid\} with absorbances at $224 \mathrm{~nm}$ and $305 \mathrm{~nm}^{10}$, or additionaly with $0.5 \mathrm{mM}$ EDTA disodium salt - at 305 or $340 \mathrm{~nm} .{ }^{11}$ Besides, it was determined at $440 \mathrm{~nm}$ by yellow complexes formation with $\mathrm{Fe}^{2+}$ ions in $80 \%$ acetic acid. ${ }^{2}$

Hence, there there is lack of simple, fast, lowcost and accurate method for quantification of Octopirox in bulk. Thus, UV method has been developed, validated and proposed in this work.

\section{MATERIALS AND METHODS}

Instrumentation. The substance was weighed using analytical balances \{Shimadzu AUX220 (10 mg - 220 g), Shimadzu Corporation, Shim Ukraine Ltd., Kyiv\}. UV spectra were recorded on UV-VIS spectrophotometer UV-2600 (190-1100 nm) \{Shimadzu Corporation, ShimUkraine Ltd., Kyiv\}.

Reagents and solutions. Ethanol was of $96 \%$ (v:v) concentration and medical purity ("Pharmasept", Lohvytsky alcohol factory, Chervonozavodske, Ukraine), distilled water was used throughout all experiments. Working substance of Octopirox was purchased from Clariant, Frankfurt, Germany.

Validation. Calibration curve. The initial standard solution $(0.05 \%)$ was prepared by dissolving $0.0500 \mathrm{gm}$ of the Octopirox in $100.0 \mathrm{ml}$ flask with 25 $\mathrm{ml}$ of $96 \%$ ethanol, stirring for $5 \mathrm{~min}$, addition of distilled water, stirring for 5 min additionally. Several aliquots of standard solution were taken to make the next series of working standard solutions in the 10-50 $\mu \mathrm{g} / \mathrm{ml}(0.001-0.005 \%)$ range by dilution of the aliquots in the ethanol-water (1:3, v:v) solution. All solutions were stored at $18-22^{\circ} \mathrm{C}$.

The calibration curve of Octopirox was constructed by UV-VIS spectrophotometric absorption data, monitored 5 times for each sample, at wavelength of maximum absorbance at $307 \pm 1 \mathrm{~nm}$ in $3 \mathrm{ml}$ cuvette with $1 \mathrm{~cm}$ layer.

The regression equation was obtained by the method of least squares for $n=5$. Regression equation: $\mathrm{Y}=$ slope $^{*} \mathrm{x}+$ intercept. Slope, intercept and regression coefficient were determined from the regression analysis calculations in Microsoft Excel 2007. ${ }^{12}$

Using this linear equation, regression coefficient $\left(\mathrm{r}^{2}\right)$ and the detection limits were determined. Accuracy: mean $\pm \mathrm{SD}$; Linearity (lowest - highest concentration while curve is linear); SE of intercept: $\sqrt{ }$ of $\sum\left(y-y^{\prime} / n\right)$, where y - standard concentration, $y^{\prime}$ found concentration; SD of intercept: SE of intercept $* \sqrt{n}$

The limit of detection (LOD): $3.3 *(\mathrm{SD}$ of intercept / slope); and the limit of quantitation (LOQ): $10^{*}$ (SD of intercept / slope). The LOD was defined by the concentration with a signal-to-noise ratio of 3 . The analyte peak in the LOQ sample should be identifiable, discrete, and reproducible with a precision of $\pm 20 \%$ and accuracy within $80 \%-120 \%$. The deviation of standards other than LOQ should be not more than $\pm 15 \%$ of the nominal concentration.

Precision (repeatability of the method) was evaluated by repeated absorption detection and the results were expressed as the mean standard deviation (SD) and the percent relative standard deviation RSD $(\%)=\mathrm{SD} /$ Mean, calculated for absorbances in all concentrations and recovery data. For intra-day analysis the samples were analyzed six times a day at 09:00 am, 11:00 am, 01:00 pm, 03:00 pm, 05:00 pm, and 07:00 pm, while for inter-day stability it was analyzed for 6 consecutive days at 09:00 am. 


\section{RESULTS AND DISCUSSION}

According to Clariant product specifications, Octopirox is white to slightly yellowish-white crystalline powder with mild characteristic odor, very slightly soluble in water, and freely soluble in ethanol, chloroform and ether. ${ }^{6}$ Its $\mathrm{pKa}$ is 7.4. The solubility of Octopirox is greatly dependent on the $\mathrm{pH}$ : it is greater in the neutral and weakly alkaline ranges than in the acidic one, due to formation of free acid form.

Considering our pharmacokinetics investigations of cosmetic and pharmaceutical dosage forms, it was decided to study Octopirox ethanol solutions; and to make the procedure cheaper, the smallest concentration of ethanol in water was studied to be appropriate for dilution. It was found that solution of $96 \%$ ethanol and distilled water in proportion 1 to 3 has made a stable and clear solution for weeks, especially, when 0.04-0.05 g of substance was taken for the first dilution in $100 \mathrm{ml}$ flask.

Validation of the method was performed in accordance to the analytical methods validation parameters. ${ }^{13}$ The precision of the method was checked by measuring absorption maxima of Octopirox standard $(10-50 \mu \mathrm{g} / \mathrm{ml})$ solutions five times. Standard deviations of each measured absorbencies were within $0.0030-0.0060$ and RSD was $0.0048-0.0138 \%$.

The linearity was evaluated by linear regression analysis, which was calculated by the least-square regression method measuring maximum absorbance of Octopirox standard solutions in the concentration range from 10 to $50 \mu \mathrm{g} / \mathrm{ml}$. The corresponding specific absorbencies, accuracy and recovery data are given in Table 1.

Table 1. Concentration of standard Octopirox solutions, their absorbances, accuracy, recovery data.

\begin{tabular}{|c|c|c|c|c|c|c|}
\hline $\begin{array}{c}\text { Standard C., } \\
\mu \mathrm{g} / \mathrm{mL}\end{array}$ & $\begin{array}{c}\overline{\mathrm{A}} \\
\text { of } 5 \text { means }\end{array}$ & SD & $\% \mathrm{RSD}$ & $\mathrm{E}_{\mathrm{cm}}^{\%}$ & $\begin{array}{c}{ }^{\mathrm{a}} \text { Found C. } \\
\mu \mathrm{g} / \mathrm{ml}\end{array}$ & ${ }^{\mathrm{b}}$ Recovery \\
\hline 10 & 0.2151 & 0.0030 & 0.0138 & 215 & 10.1485 & 101.4851 \\
\hline 20 & 0.4108 & 0.0043 & 0.0097 & 205 & 19.8366 & 99.1832 \\
\hline 30 & 0.6141 & 0.0043 & 0.0065 & 205 & 29.9010 & 99.6700 \\
\hline 40 & 0.8158 & 0.0060 & 0.0068 & 204 & 39.8861 & 99.7153 \\
\hline \multirow[t]{6}{*}{50} & 1.0215 & 0.0054 & 0.0048 & 204 & 50.0693 & 100.1386 \\
\hline & & & & & Mean, $\mathrm{n}=5$ & 100,0384 \\
\hline & & & & & $\mathrm{SD}, \mu \mathrm{g} / \mathrm{ml}$ & 0.8767 \\
\hline & & & & & $\% \mathrm{RSD}$ & 0.0078 \\
\hline & & & & & Accuracy, $\%$ & $100.0384 \pm 0.8767$ \\
\hline & & & & & Recovery, \% & $100.0384 \pm 0.0078$ \\
\hline
\end{tabular}

${ }^{\mathrm{a}}$ Found concentration: (Absorbance - intercept)/slope;

${ }^{\mathrm{b}}$ Recovery: found concentration /labeled concentration*100.

The accuracy of the method was proven by calculating the recovery at five different concentrations in table $1(100.04 \pm 0.88 \%)$. The mean percentage of recoveries was found to be $100.04 \pm$ $0.01 \%$. For example, the standard deviation of the proposed method was higher $(0.88 \mu \mathrm{g} / \mathrm{ml})$, compared to $0.14 \mu \mathrm{g} / \mathrm{ml}$ reported by RP HPLC ${ }^{9}$, but RSD data was much lower: $0.0078 \%$ against reported $0.68 \%$.
According to the Beer's law, regression coefficient, obtained similar specific absorbance (204-205), the calibration curve of Octopirox with good linearity was found in the concentration range 10.0-50.0 $\mu \mathrm{g} / \mathrm{ml}$ (Table 1, Figure 2).

Despite RP HPLC results of $0.5-3.0 \mu \mathrm{g} / \mathrm{ml}$, this method could be used in common laboratory without expensive apparatuses, ${ }^{10}$ as well as presented calibration curve - for simple and fast evaluation of unknown Octopirox solution percentage. 
Slope, intercept and correlation coefficient were determined from the regression analysis calculations (Table 2).

Table 2. Linearity, accuracy and precision of Octopirox in ethanol-water (1:3, v:v) solution.

\begin{tabular}{cc}
\hline Parameters & Results \\
\hline Slope & 0.0202 \\
Intercept & 0.0101 \\
Linearity $(\mu \mathrm{g} / \mathrm{mL})$ & $10.0-50.0$ \\
Regression equation & $\mathrm{y}=0.0202 \mathrm{x}+0.0101$ \\
$\mathrm{r}^{2}$ & 0.999 \\
SE of intercept & 0.0032 \\
SD of intercept & 0.0072 \\
LOD $(\mu \mathrm{g} / \mathrm{mL})$ & 1.1831 \\
LOQ $(\mu \mathrm{g} / \mathrm{mL})$ & 3.5852 \\
\hline
\end{tabular}

The limit of detection (LOD) was found to be $1.18 \mu \mathrm{g} / \mathrm{ml}$, while the limit of quantification (LOQ) was $3.58 \mu \mathrm{g} / \mathrm{ml}$.

The ruggedness of the method was determined by performing the same assay by different researches and performing the assay for $0.0035 \%$ Octoripox ethanol-water (1:3) solution during week to check its reproducibility. The results were found to be highly reproducible during the day - RSD was $0.0032 \%$, and during the week increased to $0.076 \%$, still with high precision (Table 3). It's worth to mention, that maximum absorbance wavelength shifted to $306 \mathrm{~nm}$ in $3 \mathrm{~h}$, due to protonation of Octoripox, and in the next three weeks it was found at $302-301 \mathrm{~nm}$.

Table 3. The intra-day and inter-day precision of $0.0035 \%$ Octoripox solution in ethanol-water $(1: 3, v: v)$.

\begin{tabular}{ccc}
\hline$\#$ & Intra-day & Inter-day \\
\hline 1 & 0.7226 & 0.7162 \\
2 & 0.7215 & 0.7245 \\
3 & 0.7217 & 0.7301 \\
4 & 0.7202 & 0.7321 \\
5 & 0.7178 & 0.7275 \\
6 & 0.7162 & 0.7203 \\
Mean & 0.7200 & 0.7251 \\
SD & 0.0025 & 0.0060 \\
$\%$ RSD & 0.0032 & 0.0076 \\
\hline
\end{tabular}

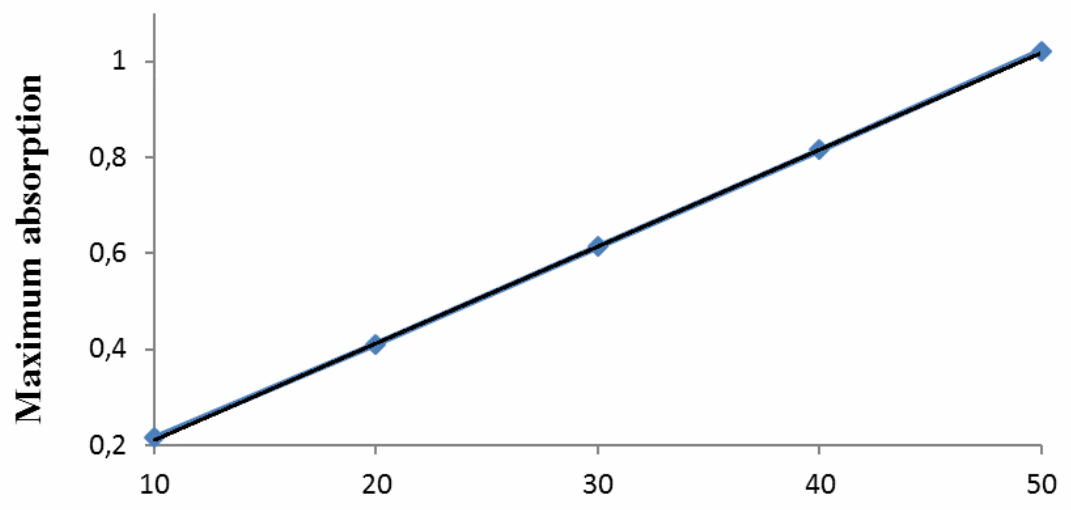

Concentration, $\mu \mathrm{g} / \mathrm{ml}$
To determine the robustness of the method, experimental conditions like room temperature, stirring time, different ethanol series and distilled water were checked. It is very important to dilute Octoripox firstly in the $96 \%$ ethanol, because in case of usage ready-to-use ethanol - water (1:3, v:v) solution, substance was worse soluble, even in the concentration $0.05 \%$ and the next day opacity appeared. Furthermore, stirring was essential to obtain accurate results. Additionally, the second dilution in the higher amount of solvent like $50 \mathrm{ml}$ also shifted the maximum absorbance results to the 
lower values. In addition, usage of different distilled water series also caused its $307 \pm 1 \mathrm{~nm}$ due to different $\mathrm{pH}$. The temperature very slightly effected the results, still the $20-22^{\circ} \mathrm{C}$ was the most appropriate one. Hence, to obtain absorption in the range 0.6-0.9 and to detect the amount of Octopirox in pure substance, the next method is proposed.

Quantitatively $0.040-0.0550$ of Octopirox was placed in the $100.0 \mathrm{ml}$ flask, dissolved with $25.0 \mathrm{ml}$ of $95 \%$ ethanol, stir for $5 \mathrm{~min}$, add distilled water to obtain $0.045-0.055 \%$ solution and stir for $5 \mathrm{~min}$. Then quantitatively transfer $2.00 \mathrm{ml}$ of the obtained solution in $25.00 \mathrm{ml}$ flask, add ethanol-water (1:3) solution to obtain final $0.0036-0.0044 \%$ solution, stir for $5 \mathrm{~min}$. Determine the concentration of Octopirox by measuring maximum UV absorption at wavelength of $307 \pm 1 \mathrm{~nm}$ in comparison to ethanolwater (1:3, v:v) solution in $3 \mathrm{~mL}$ cuvette with $1 \mathrm{~cm}$ layer.

The sample concentration is calculated in accordance with the next equation:

$\mathrm{C}, \mu \mathrm{g} / \mathrm{ml}$ of final solution $=\frac{\mathrm{A} i-0.0101}{0.0202}$

where $\mathrm{A} i$ - maximum absorption of the investigated sample in ethanol-water (1:3, v:v) at 307 $\pm 1 \mathrm{~nm}$ in $3 \mathrm{ml}$ cuvette with $1 \mathrm{~cm}$ layer;

Or, in comparison to the measured absorbance of standard solution:

$\mathrm{C}, \%$ of final solution $=\frac{\mathrm{A} i * 0.004}{0.8181}$,

where $\mathrm{A} i$ - maximum absorption of the investigated sample in ethanol-water (1:3, v:v) at 307 $\pm 1 \mathrm{~nm}$ in $3 \mathrm{ml}$ cuvette with $1 \mathrm{~cm}$ layer; 0.004 concentration (\%) of the standard solution with absorbance of 0.8181 at $307 \pm 1 \mathrm{~nm}$. or concentration in the initial sample:

$\mathrm{C}, \%(\mathrm{w} / \mathrm{V})$ in bulk $=\frac{\mathrm{A} i \cdot \mathrm{C}_{0} \cdot 100.0 \cdot 25.00}{\mathrm{~A}_{0} \cdot V p \cdot l \cdot a}$,

where $\mathrm{Ai}$ - maximum absorption of the final experimental sample solution;

$\mathrm{C}_{0}$ - concentration of the Octopirox standard solution is $0.004 \%$;
100.0, 25.00 - flasks dilutions volume, $\mathrm{ml}$;

$\mathrm{A}_{0}$ - maximum absorption of $0.004 \%$ standard solution at $307 \pm 1 \mathrm{~nm}$ is 0.8181 ,

$\mathrm{V} p$ - sample volume taken by pipette is $2 \mathrm{ml}$;

1 -cuvette layer is $1 \mathrm{~cm}$;

a - sample weight, g.

\section{CONCLUSIONS}

It was found, that Octopirox in ethanol-water $(1: 3, \mathrm{v}: \mathrm{v})$ solution could be simple, fast and accurate as qualitatively and quantitatively determined by UV spectroscopy by the maximum absorbance at $307 \pm 1$ $\mathrm{nm}$. The exact method of determination is proposed. Validation showed, that calibration curve had good linearity $\left(r^{2}=0.99\right)$ in the concentration range 10-50 $\mu \mathrm{g} / \mathrm{ml}$. The LOD was calculated to be $1.18 \mu \mathrm{g} / \mathrm{ml}$ and LQD - $3.59 \mu \mathrm{g} / \mathrm{ml}$. Such criteria like accuracy, precision, robustness and ruggedness also showed high validity and reproducibility, noticing the high importance of substance first step dilution in $96 \%$ ethanol.

\section{REFERENCES}

1. Pirocton-Olamin. http://www.wikiwand.com/de/PiroctonOlamin.

2. Octopirox. Antidandruff active ingredient. Hoechst AG. EHOE. 4815E-0391/134. http://www.fda.gov/ohrms/dockets/ dailys/04/oct04/101904/04n-0050-rpt0001-E-03-Hoechstvol7.pdf.

3. Unilever Plc, Unilever N.V. Antimicrobial Personal Care Compositions. Patent WO 1998023258 A1. Issued date June 04, 1998. https://www.google.com/patents/WO1998023258 $\mathrm{A} 1 ? \mathrm{cl}=\mathrm{en} \& \mathrm{hl}=\mathrm{ru}$.

4. Dubini, F., Bellotti, M.G., Frangi, A., Monti, D., Saccomani, L. 2005. In vitro antimycotic activity and nail permeation models of a piroctone olamine (octopirox) containing transungual water soluble technology. ArzneimittelForschung. 55, 478-83. doi:10.1055/s-0031-1296892.

5. Safety data sheet. Octopirox. Clariant Corporation. USA. http://www.essentialingredients.com/msds/Octopirox.pdf.

6. Octopirox - 105273. Revision: 3. Product Specification. Höchst/Germany. Date of Issue: 03/18/2014. http://www.essentialingredients. com/spec/Octopirox.pdf 
7. Cosmetics. EN16342:2013. Analysis of cosmetic products Quantitative determination of zinc pyrithione, piroctone olamine and climbazole in surfactant containing cosmetic anti-dandruff products. BSI British Standards. doi: $10.3403 / 30252298$ u.

8. Stability test of Octopirox (piroctone olamine) substance for 3 years at room temperature, Dr. Futterer, Hoechst AG, 30.06.1981.http://www.fda.gov/ohrms/dockets/dailys/04/oct0 4/101904/04n-0050-rpt0001-E-11-Futterer-vol7.pdf.

9. Determination of Octopirox in Shampoos by HPLC, Clariant $\mathrm{GmbH}$, 02.03.2001. http://www.fda.gov/ohrms/dockets/ dailys/04/oct04/101904/04n-0050-rpt0001-E-20-ClariantGmbH-2001-vol7.pdf.

10. Chao, L. 2001. Simultaneous determination of four antidandruff agents including octopirox in shampoo products by reversed-phase liquid chromatography. Int. J. Cosmet. Sci. 23, 183-188. doi:10.1046/j.1467-2494.2001.00090.x.
11. Gagliardi, L., Multari, G., Cavazzutti, G., De Orsi, D., Tonelli, D. 1998. HPLC determination of ciclopirox, octopirox and pyrithiones in pharmaceuticals and antidandruff preparations. J. Liq. Chrom. Relat. Tech. 21, 2365-2373. doi:10.1080/ 10826079808000544.

12. Etheridge, D. 2007. Microsoft Office Excel 2007 Data Analysis: Your visual blueprint for creating and analyzing data, Charts, and PivotTables. 3rd ed. Wiley Publishing, Indianapolis, Indiana.

13. Validation of analytical procedures: Methodology. 1996.

Geneva Q2B. Incorporated in Q2(R1), 2005.

http://www.ich.org/fileadmin/Public_Web_Site/ICH_Product s/Guidelines/Quality/Q2_R1/Step4/Q2_R1__Guideline.pdf. 